\title{
Consolidation of Nanocrystalline Nd-Fe-B Powder by Hydrostatic Extrusion at High Temperature
}

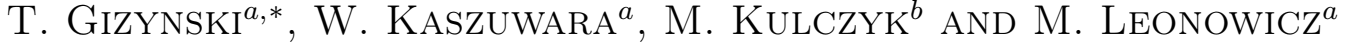 \\ ${ }^{a}$ Warsaw University of Technology, Faculty of Materials Science and Engineering, \\ Wołoska 141, 02-507 Warsaw, Poland \\ ${ }^{b}$ Institute of High Pressure Physics, Polish Academy of Sciences, Sokołowska 29/37, 01-142 Warsaw, Poland

\begin{abstract}
Hydrostatic extrusion is a modern method of shaping material microstructure and properties. Hydrostatic
\end{abstract} \\ extrusion can also be successfully used for consolidation of hard magnetic powders. The effect of extrusion tem- \\ perature, within the range of $700-800^{\circ} \mathrm{C}$, on the magnetic properties of the bulk, final product was studied. A \\ commercial MQU-F42 powder, dedicated to hot pressing, was placed in copper capsules and initially cold com- \\ pacted up to $60 \%$ of the theoretical density. Subsequently, the billet was heated in an oven to temperatures 700 \\ and $800^{\circ} \mathrm{C}$, respectively and subjected to hydrostatic extrusion. The extruded product had a form of a copper \\ rod, with the $\mathrm{Nd}-\mathrm{Fe}-\mathrm{B}$ core, having $96 \%$ of theoretical density (true strain 1.85 after extrusion at $800^{\circ} \mathrm{C}$ ). The \\ extrusion process led to deterioration of the coercivity, for which coarsening of the $\mathrm{Nd}_{2} \mathrm{Fe}_{14} \mathrm{~B}$ grains was blamed. \\ In order to prove this hypothesis, the starting powder was annealed in a temperature range of $550-900{ }^{\circ} \mathrm{C}$ for \\ various times. The crystallite size, measured after annealing by the X-ray diffraction method, showed that with \\ extension of time and elevation of the temperature the crystallite size increases, however the dominating parameter \\ is the temperature. Correlation of the crystallite size with temperature indicates that when the crystallites are \\ larger than $80 \mathrm{~nm}$ the magnetic properties dramatically decrease. Additionally, after $\mathrm{HE}$ at $800{ }^{\circ} \mathrm{C}$ micrometric \\ size Nd-rich phase appear in the microstructure. The $\mathrm{Nd}$ is squeezed from the grain boundary of the $\mathrm{Nd}_{2} \mathrm{Fe}_{14} \mathrm{~B}$ \\ phase leading to non-isolated grains, which also contributes to the deterioration of the coercivity.
}

DOI: 10.12693/APhysPolA.131.1260

PACS/topics: $75.50 . \mathrm{Ww}$

\section{Introduction}

Hydrostatic extrusion (HE) is a well-known method of shaping material properties and microstructure [1]. It has also been reported that HE can be successfully applied to processes of consolidation of hard magnetic powders [2], however, powder metallurgy is still the most commonly used method of powder densification [3]. The undoubted advantage of HE is the very short time of the extrusion, and tri-axial state of stress, continuously acting at the billet during the entire process of hydrostatic extrusion.

As it has been presented [4], HE can be successfully used to densify hard magnetic $\mathrm{Nd}-\mathrm{Fe}-\mathrm{B}$ nanocrystalline powders. As a result, the final density of the materials depends on the applied strain and temperature of the process. Extrusion performed at room temperature allowed one to achieve specimens having $90 \%$ of theoretical density. Higher densities, 94 and $96 \%$ were obtained for materials extruded at temperatures $700^{\circ} \mathrm{C}$ and $800^{\circ} \mathrm{C}$, respectively. However, extruding materials at high temperatures can lead to crystallite size growth, which results in deterioration of the coercivity and remanence. Also, a presence of the Nd-rich phase, squeezed from grain boundaries in the specimen extruded at $800^{\circ} \mathrm{C}$ was

\footnotetext{
* corresponding author; e-mail:

tomasz.gizynski@inmat.pw.edu.pl
}

observed, which also may act on decrease of magnetic properties.

Preliminary studies showed that the grain growth caused by the elevated process temperature causes a decrease of the magnetic properties. Additionally, the Ndrich phase, squeezed from the grain boundary, fills small pores, and leads to the formation of non-isolated grains, which may also affect the coercivity and remanence.

This study concentrates directly on the influence of grain growth and other phenomena on the observed deterioration of magnetic properties of hydrostatically extruded $\mathrm{Nd}-\mathrm{Fe}-\mathrm{B}$ powder at two temperatures, $700^{\circ} \mathrm{C}$ and $800^{\circ} \mathrm{C}$, respectively.

\section{Experimental}

For this research high coercivity $\mathrm{Nd}-\mathrm{Fe}-\mathrm{B}$ powder, provided by Magnequench and dedicated for hot working, was used. Its composition was (at.\%) $\mathrm{Nd}_{13.95} \mathrm{Fe}_{73.27} \mathrm{~B}_{5.49} \mathrm{Co}_{6.72} \mathrm{Ga}_{0.57}$. The polycrystalline powder had a form of $25 \mu \mathrm{m}$ thick flakes, with much greater other dimensions. Its particles were composed of nanocrystalline grains of the $\mathrm{Nd}_{2} \mathrm{Fe}_{14} \mathrm{~B}$ phase, having a mean size of around $30 \mathrm{~nm}$. The theoretical density of the $\mathrm{Nd}-\mathrm{Fe}-\mathrm{B}$ powder was $7.51 \mathrm{~g} / \mathrm{cm}^{3}$.

The powder was initially densified in a copper capsule to reach $60 \%$ of its theoretical density. Subsequently, the capsule was sealed under vacuum by a copper plug and welded with an electron beam to prevent contact with air or pressurized working fluid in the chamber during the entire technological processes. The billet was heated up 
in an external oven and transferred to the working chamber. After closing, the chamber was filled with oil having room temperature. Within the time of transferring from the oven to the beginning of the extrusion process the billet cools down, depending on its size, by $100-150^{\circ} \mathrm{C}$. Due to the technical specifics of hydrostatic extrusion, a detailed control of the temperature during the process is impossible.

Two processes of hydrostatic extrusion were applied, at $700{ }^{\circ} \mathrm{C}$ and $800^{\circ} \mathrm{C}$, respectively. These values were the temperatures to which billets were heated up before the extrusion. The temperatures were selected to be below and above the melting temperature of the Nd-rich phase (ca. $655^{\circ} \mathrm{C}[5]$ ), respectively. The billets were extruded in single-stage processes with the same diameter reduction ratio of 1,85 , defined as $\varepsilon=\ln \left(d_{1}^{2} / d_{2}^{2}\right)$, where $d_{1}$ and $d_{2}$ are the initial and final rod diameter, respectively. During the hydrostatic extrusion, the billet (3) surrounded by fluid (2) is compressed in a container (4) by a plunger (1). The fluid pressure forces the billet through the die (5) to create the extruded product in a form of a copper rod with $\mathrm{Nd}-\mathrm{Fe}-\mathrm{B}$ core (6) (Fig. 1).

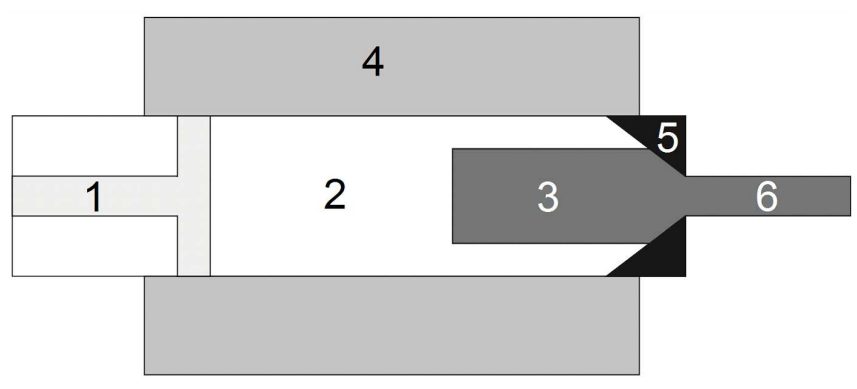

Fig. 1. Hydrostatic extrusion scheme.

The magnetic properties of the samples were examined using a Lake Shore vibrating sample magnetometer, and QuantumDesign Physical Property Measurement System PPMS. Samples were also characterized by X-ray diffraction (XRD) measurements with $\mathrm{Cu} K_{\alpha}$ radiation. The crystallite size of $\mathrm{Nd}_{2} \mathrm{Fe}_{14} \mathrm{~B}$ grains was determined using the Scherrer method. The microstructure of the samples was observed using a ZEISS SEM microscope. Magnetization versus temperature dependence was measured in a $80 \mathrm{kA} / \mathrm{m}$ field, and the specimens were previously magnetized in a $1600 \mathrm{kA} / \mathrm{m}$ field.

\section{Results}

The magnetic and physical properties of the samples (remanence $B_{r}[\mathrm{~T}]$, coercivity $H_{c}[\mathrm{kA} / \mathrm{m}]$, diameter reduction $R\left(d_{1}^{2} / d_{2}^{2}\right)$, true strain $\varepsilon$, and crystallite size $s[\mathrm{~nm}]$ ) obtained by hydrostatic extrusion performed at $T=700^{\circ} \mathrm{C}$ and $800^{\circ} \mathrm{C}$, respectively, are presented in Table I. Precise analysis of these results showed that the extrusion process led to the deterioration of the coercivity, for which coarsening of the $\mathrm{Nd}_{2} \mathrm{Fe}_{14} \mathrm{~B}$ grains was blamed.

\section{TABLE I}

Properties of samples extruded hydrostatically at 700 and $800^{\circ} \mathrm{C}$.

\begin{tabular}{c|c|c|c|c|c}
\hline \hline$T$ & $B_{r}[\mathrm{~T}]$ & $H_{c}[\mathrm{kA} / \mathrm{m}]$ & $R$ & $\varepsilon$ & $s[\mathrm{~nm}]$ \\
\hline $\mathrm{HE} 700700^{\circ} \mathrm{C}$ & 0.718 & 1077 & 6.34 & 1.85 & 65 \\
$\mathrm{HE} 800800^{\circ} \mathrm{C}$ & 0.654 & 682 & 6.38 & 1.85 & 95
\end{tabular}

In order to prove this hypothesis, the starting powder was placed in quartz capsules, sealed in vacuum conditions, and annealed at the temperature range of 550 $900^{\circ} \mathrm{C}$ for three different times $-10,30$, and $60 \mathrm{~min}$, respectively. After annealing, each powder was examined using an XRD method. Due to the lack of the internal stress after annealing, crystallite sizes were calculated using the Scherrer equations [6]. Additionally, to determine dependence of the annealing temperatures and crystallite sizes after annealing on both coercivity and remanence, the VSM measurements of the powders were performed.

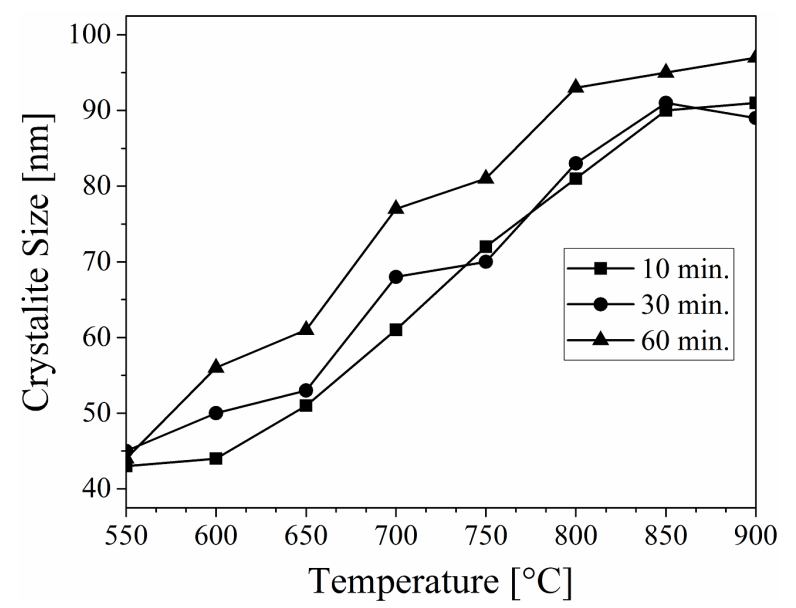

Fig. 2. Crystallite size dependence on annealing temperature.

One can notice (Fig. 2), that with extension of time and elevation of the annealing temperature the crystallite size increases, however the dominating parameter is the temperature. Collation of magnetic properties with annealing temperatures (Fig. 3) shows that annealing the powder in the temperature range of $600-900{ }^{\circ} \mathrm{C}$ leads to deterioration of the coercivity. Also a drop of the remanence was observed. This phenomena occurs particularly intensively at the temperature range of $700-800^{\circ} \mathrm{C}$ and is caused by intense crystallite growth of the $\mathrm{Nd}_{2} \mathrm{Fe}_{14} \mathrm{~B}$ phase. This leads to the conclusion that precise control of the temperature parameter during hydrostatic extrusion plays a key role in this process. Additionally, comparison of annealed powder with extruded material at the same conditions shows that the coercivity of the powders annealed at 700 and $800^{\circ} \mathrm{C}$ is much higher and close to the values obtained for extruded materials, respectively. Squeezing of Nd-rich phase from the grain boundaries area does not affect on the deterioration of 
magnetic properties. During the hydrostatic extrusion process carried out at $800^{\circ} \mathrm{C}$, the $\mathrm{Nd}_{2} \mathrm{Fe}_{14} \mathrm{~B}$ phase could become partly destructed, which may lead to formation of another phase, similar to the phase obtained by hydrostatic extrusion at room temperature [7].

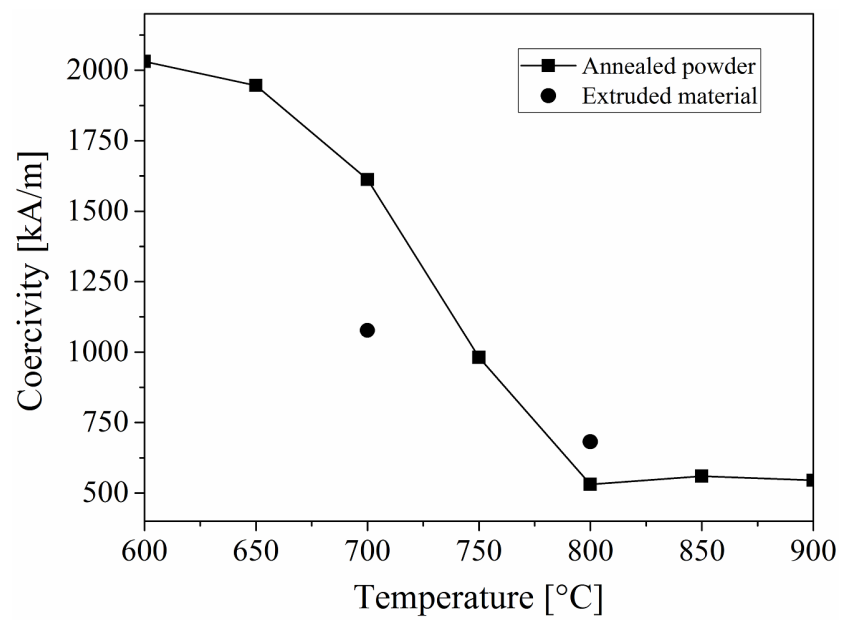

Fig. 3. Dependence of coercivity on annealing temperature of powders (60 min annealing time) and extruded materials.

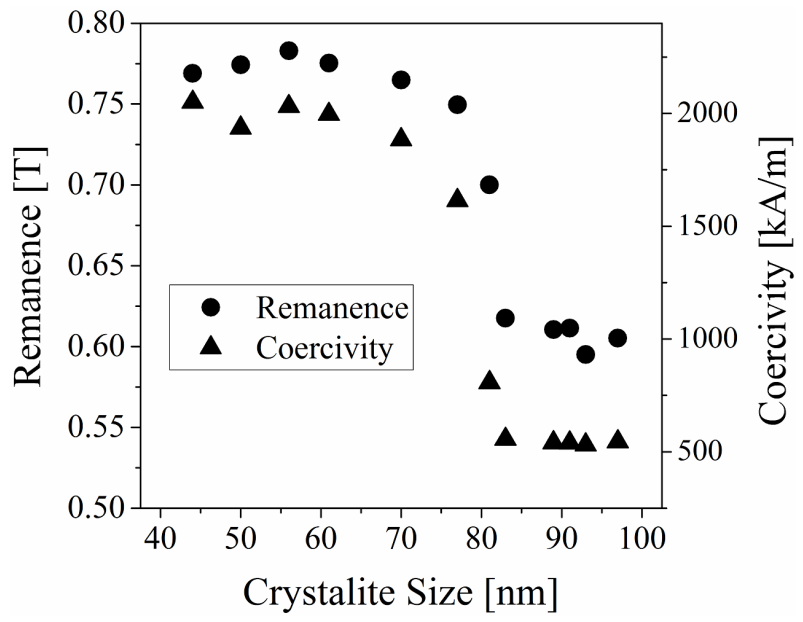

Fig. 4. Dependence of the remanence and coercivity on the crystallite size of powder annealed for various times.

Collation of the coercivity and remanence values, for various crystallite sizes, shows that when the crystallites exceed $80 \mathrm{~nm}$, the properties abruptly drop (Fig. 4). This crystallite size is close to the single domain particle size, which is equal to $75-130 \mathrm{~nm} \mathrm{[8].} \mathrm{The} \mathrm{observed} \mathrm{discrep-}$ ancy might be caused by underestimation of the crystallite size by the Scherrer methods and by the fact that the crystallites are not perfectly isolated from each other. On this basis, one can conclude that the crystallite sizes in the materials extruded at $700^{\circ} \mathrm{C}$ and $800^{\circ} \mathrm{C}$ are smaller and larger, respectively, than the single domain particle size, for this material, which explains the much lower

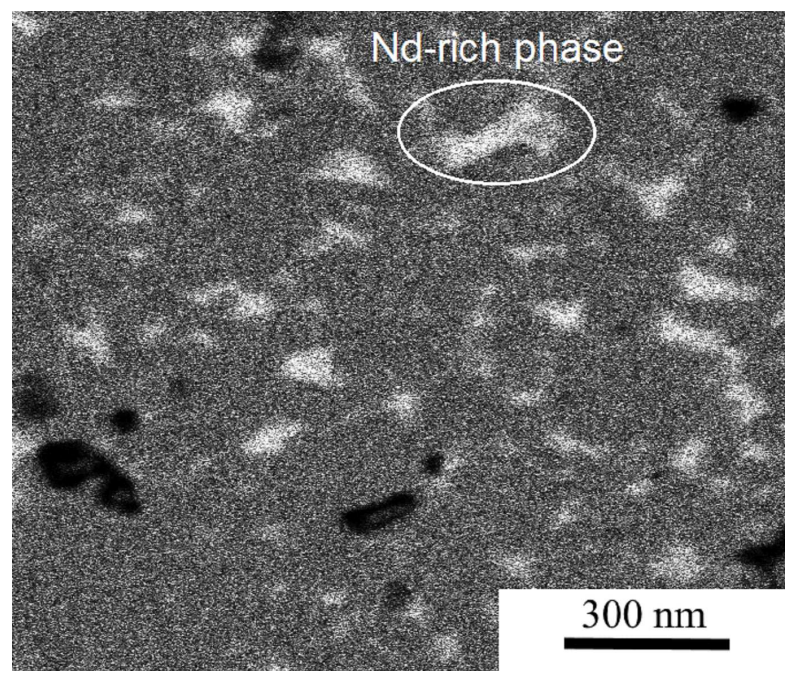

Fig. 5. Microstructure of the sample extruded at $800^{\circ} \mathrm{C}$.

value of coercivity of the sample extruded at $800^{\circ} \mathrm{C}$. After hydrostatic extrusion, to provide high magnetic properties, the crystallites should not exceed $80 \mathrm{~nm}$ size.

$\mathrm{HE}$ at $800^{\circ} \mathrm{C}$ leads to the appearance of micrometric size areas of the Nd-rich phase in the microstructure, as presented in Fig. 5. In the course of extrusion this phase is liquid and is partially extracted out from the grain boundaries to fill small pores. The Nd squeezed from the grain boundary of the $\mathrm{Nd}_{2} \mathrm{Fe}_{14} \mathrm{~B}$ phase may lead to non-isolated grains. A precise analysis of this phenomenon shows that deterioration of the coercivity depends mostly on grain growth, and the grains rather remain isolated. The influence of this phenomenon on decrease of the magnetic properties is difficult to determine, however it should not be a major cause of the coercivity drop.

Figure 6 presents magnetization versus temperature curves for the specimen single-stage extruded at $800^{\circ} \mathrm{C}$ and for the initial powder. Analysis of these dependences showed a presence of a deflection point for both specimens. An abrupt drop of the magnetization, at a temperature of about $400^{\circ} \mathrm{C}$ is characteristic of the Curie temperature for the $\mathrm{Nd}_{2}(\mathrm{Fe}, \mathrm{Co}){ }_{14} \mathrm{~B}$ phase. No other deflections were observed during these experiments. The $\mathrm{X}$-ray phase analysis, performed after hydrostatic extrusion at $800^{\circ} \mathrm{C}$, did not show any changes in the phase constitution or peaks intensity and locations. However, magnetization of the extruded specimen is much higher than the initial powder, even above the $400^{\circ} \mathrm{C}$. It may be caused by some quantity of iron precipitates. They might appear due to decomposition of the $\mathrm{Nd}_{2} \mathrm{Fe}_{14} \mathrm{~B}$ phase, caused by strain, as shown in the experiments performed at room temperature [7]. To confirm these suspicions, a Mössbauer study was made for the selected specimens. Precise analysis showed a presence of another phase in the specimen extruded at $800^{\circ} \mathrm{C}$, which confirms partial decomposition of $\mathrm{Nd}_{2} \mathrm{Fe}_{14} \mathrm{~B}$ phase. 


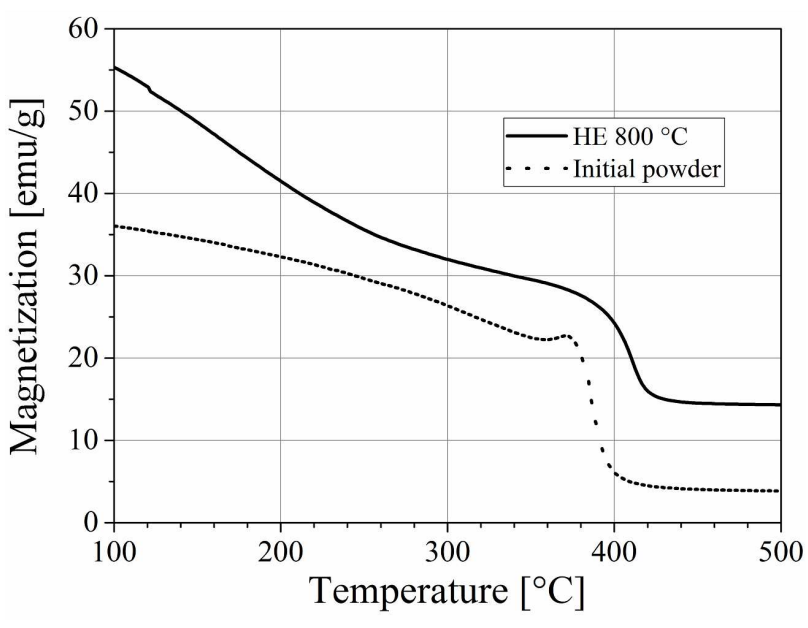

Fig. 6. Magnetization versus temperature for the specimen extruded at $800^{\circ} \mathrm{C}$ and initial powder.

\section{Summary}

Hydrostatic extrusion at high temperature can be successfully used to densify hard magnetic powders. The experimental data provides evidence that hydrostatic extrusion of the $\mathrm{Nd}-\mathrm{Fe}-\mathrm{B}$ powder at temperatures up to $800^{\circ} \mathrm{C}$ leads to deterioration of the coercivity and remanence. This effect is caused mainly by coarsening of the $\mathrm{Nd}_{2} \mathrm{Fe}_{14} \mathrm{~B}$ grains during extrusion processes, and also by decomposition and other transformations of the $\mathrm{Nd}_{2} \mathrm{Fe}_{14} \mathrm{~B}$, similar to the processes carried out at room temperature. Squeezing from the grain boundaries of the $\mathrm{Nd}_{2} \mathrm{Fe}_{14} \mathrm{~B}$ phase does not substantially break the magnetic isolation of the grains, and does not affect the magnetic properties. Temperature seems to be a dominating parameter of the hydrostatic extrusion process, and its precise control is highly important.

\section{Acknowledgments}

The study was financed within the project co-funded by the European Union in Operational Programme Innovative Economy POIG 01.01.102.00/10 (ZAMAT). Hydrostatic extrusion processes were performed at the Institute of High Pressure Physics, Polish Academy of Science. $\mathrm{Nd}-\mathrm{Fe}-\mathrm{B}$ powder used in these experiments was provided by Magnequench.

\section{References}

[1] W. Pachla, M. Kulczyk, A. Świderska-Środa, M. Lewandowska, H. Garbacz, A. Mazu, K.J. Kurzydłowski, in: Proc. 9th Int. Conf. on Mat. Forming ESAFORM-2006, Glasgow 2006, p. 535.

[2] W. Pachla, A. Morawski, P. Kovac, I. Husek, A. Mazur, T. Lada, R. Diduszko, T. Melisek, V. Strbık, M. Kulczyk, Supercond. Sci. Technol. 19, 1 (2006).

[3] M. Sagawa, S. Fujimura, M. Togawa, Y. Matsuura, J. Appl. Phys. 55, 2083 (1984).

[4] W. Kaszuwara, M. Kulczyk, M. Leonowicz, T. Gizynski, B. Michalski, IEEE Trans. Magn. 50, 1 (2014).

[5] G. Schneider, E.-T. Henig, G. Petzow, H.H. Stadelmaier, Z. Metallkde 77, 755 (1986).

[6] D. Oleszak, A. Olszyna, Composites R4, 284 (2004).

[7] T. Gizynski, W. Kaszuwara, P. Pawlik, M. Kulczyk, M. Leonowicz, B. Michalski, Acta Phys. Pol. A 127, 626 (2015).

[8] Er. Girt, Kannan M. Krishnan, G. Thomas, E. Girt, Z. Altounian, J. Magn. Magn. Mater. 231, 219 (2001). 